\title{
Towards intelligibility: Designing short pronunciation courses for advanced field experts
}

Alice Henderson

\section{OpenEdition}

\section{Journals}

\section{Electronic version}

URL: http://journals.openedition.org/asp/369

DOI: $10.4000 / a s p .369$

ISBN: 978-2-8218-0406-7

ISSN: 2108-6354

\section{Publisher}

Groupe d'étude et de recherche en anglais de spécialité

Printed version

Date of publication: 1 November 2008

Number of pages: $89-110$

ISSN: 1246-8185

\section{Electronic reference}

Alice Henderson, «Towards intelligibility: Designing short pronunciation courses for advanced field experts », ASp [Online], 53-54 | 2008, Online since 01 November 2011, connection on 01 May 2019. URL : http://journals.openedition.org/asp/369 ; DOI : 10.4000/asp.369

This text was automatically generated on 1 May 2019.

Tous droits réservés 


\title{
Towards intelligibility: Designing short pronunciation courses for advanced field experts
}

\author{
Alice Henderson
}

1 Many teachers of short pronunciation courses face a tremendous challenge when they have to select aspects of spoken English to focus on. They choose on the basis of their own training or experience, or may look to textbooks for a list of features to teach. However, because the number of non-native speakers of English is now greater than the number of native speakers, leading to cultural and linguistic diversity in a huge variety of interactional contexts and genres, such a list is bound to be imperfect. Teachers, therefore, need to decipher the current debate over norms and standards, which can be expressed in two related questions: should native-like pronunciation always be the goal and which variety of English should be taught? For the short course referred to in this paper, native-like pronunciation was not necessarily the goal. Field experts made progress towards their own target pronunciation which was worked out with the teacher in relation to: their level of proficiency, their objectives and the features that research has shown to be important for intelligibility when presenting a paper to a mixed audience of native and non-native speakers (NSs and NNSs). This paper refers to this course as part of an exploratory study, using the latter to provide concrete examples to frame the theoretical issues. For this reason, the context will be described first. This is followed by a critical overview of issues related to spoken English and to the needs and perceptions of speakers and listeners. The findings of the exploratory study are also briefly discussed. 


\section{Context}

\subsection{Participants and objectives}

2 The course, which is held annually at a French university, involves groups of 10-12 accomplished researchers and doctoral students in applied linguistics. They are motivated adults, aged 23-58. Five participants were selected for the exploratory study because they represent a variety of mother tongues and proficiency levels. Speaker 1 (S1) is a native speaker of Bulgarian who is also fluent in Russian, German and French. S2 is a native French speaker who speaks German quite well and is fluent in French Sign Language. S3 is also a native French speaker but does not feel she masters any other language. S4 is from Japan and speaks French fluently. S5 is a native Greek speaker who is fluent in French.

3 Although the nature of their motivation varied, all the participants wanted to improve their spoken English and to feel more at ease when participating in international conferences. Conferences involve both unpredictable interactional language and the highly normed format and register of the conference presentation. Presentations can be done in several different ways and, while there are undoubtedly field-specific differences, PowerPoint use seems widespread. As one researcher in psychology categorically states: "Everybody uses PowerPoint. If you show up with transparencies, everyone laughs. If you show up with nothing, everyone leaves." (Desrichard 2008)

In terms of delivery, Banks states that "Most people would accept that reading a prepared text is hardly the best method of communicating a message" (1999: 214) and that speaking from notes should be the training objective. However, affective factors also have a powerful influence on performance and should not be ignored. Rehearsing a conference paper by reading it aloud increases field experts' confidence in their spoken English, in part because it creates optimal performance conditions. During such practice, specific pronunciation difficulties may come to light and be addressed with the teacher. The participants in the present study always use PowerPoint for conference presentations. PowerPoint can be strategically used to provide disambiguating visual context for terms such as "multi-modal monolingual roles" or "hypothesis", which are difficult to articulate and have no synonyms. It is easy to point to them on a slide and makes it easier for the audience to understand. This solution to a pronunciation problem has little to do with modifying articulation but it can make a speaker's message more intelligible. Several of the participants in the course have used PowerPoint as a "crutch", initially reading aloud but improving to speak semi-spontaneously from their notes or slides. From this point of view, reading aloud can be seen as a valid training objective.

Using a read-aloud task begs the question of how writing and speech are different. Chafe and Danielewicz (1987) describe texts as "integrated" or "fragmented" in relation to structure, and "involved" or "detached" in relation to degree of interaction. Written text tends to be integrated (propositionally dense, highly structured) and detached whereas spoken text tends to be fragmented and involved (interacting with its audience). Speech and writing are seen as situated on a continuum of features, with casual conversation and academic papers at the two extremes (ibid.). The degree of planning has also been studied; planned discourse, such as academic lectures, is referred to as being "thought out and organized (designed) prior to its expression" and unplanned discourse, such as 
conversation, is referred to as lacking "forethought and organizational preparation" (Ochs cited in Danielewicz 1984: 245). In terms of lexical density, written and planned texts are denser than spoken and unplanned texts (Halliday [1985] 1989; Stubbs 1986; Biber 1988). It therefore becomes difficult to "classify" read-aloud, conference presentations because they are highly integrated and planned, like written text, and yet they are spoken.

In a similar vein, in her study of academic lectures from the BASE corpus, Nesi (2001) found that density is affected by the medium of delivery (spoken or written) and the presence or absence of feedback. Lectures were denser if no interaction was expected. Prepared speech was usually denser, with the highest densities produced by professional speakers, who rely on much formulaic and rehearsed language. Speed of delivery was also affected by interactivity (in that the speech rate was slower when there was less potential for interruption) and preparation levels (spontaneous speech was delivered at a higher speed). ${ }^{1}$ Both density and speed can be modified in a short amount of teaching time; therefore, the participants in the present study were encouraged to speak more slowly than "normal" and they did so.

\subsection{Contrastive analysis}

7 A contrastive analysis is feasible and can help teachers to understand those features which, in relation to English, are different in the participants' native languages. Table 1 shows some of the relevant features for the participants in the exploratory study. These are only some of the features which research indicates are essential to intelligibility.

Table 1. Summary of Four Features of Participants' Native Languages ${ }^{2}$

\begin{tabular}{|c|c|c|c|c|}
\hline & L1 French & L1 Japanese & L1 Greek & L1 Bulgarian \\
\hline Timing & syllable & mora or syllable & syllable & syllable \& stress \\
\hline $\begin{array}{l}\text { Tonic } \\
\text { Stress/ } \\
\text { Focus }\end{array}$ & $\begin{array}{l}\text { via syntactic } \\
\text { features }\end{array}$ & $\begin{array}{l}\text { intonation not used } \\
\text { to highlight old/ } \\
\text { new information }\end{array}$ & $\begin{array}{l}\text { (information } \\
\text { unavailable) }\end{array}$ & $\begin{array}{l}\text { "like English" } \\
\text { (anecdotal evidence } \\
\text { from a native } \\
\text { speaker) }\end{array}$ \\
\hline $\begin{array}{l}\text { Word/ } \\
\text { Lexical } \\
\text { Stress }\end{array}$ & $\begin{array}{l}\text { fixed } \\
\text { (final); } \\
\text { unstressing does } \\
\text { not involve } \\
\text { vowel reduction }\end{array}$ & $\begin{array}{l}\text { pitch accent (high/ } \\
\text { low) to emphasise } \\
\text { words; } \\
\text { all syllables equal } \\
\text { length }\end{array}$ & $\begin{array}{l}\text { dynamic \& variable; } \\
\text { primary stress (and } \\
\text { maybe secondary } \\
\text { stress); vowels } \\
\text { somewhat longer }\end{array}$ & $\begin{array}{l}\text { variable, stress= } \\
\text { louder, longer; } \\
\text { can be } \\
\text { distinctive; } \\
\text { mostly primary }\end{array}$ \\
\hline $\begin{array}{l}\text { Consonant } \\
\text { Clusters }\end{array}$ & $\begin{array}{l}\text { Final } c+l e= \\
\text { tend to insert } \\
\text { schwa }+ \text { stress } \\
\text { final syllable }\end{array}$ & $\begin{array}{l}\text { Few C clusters, tend } \\
\text { to insert epenthetic } \\
\text { vowels + short } \\
\text { vowels after final } \\
\text { Cs }\end{array}$ & $\begin{array}{l}\text { Word-final C clusters } \\
\text { exist; nasal clusters } \\
\text { in medial position }\end{array}$ & $\begin{array}{l}\text { Word-final Cs } \\
\text { devoiced }\end{array}$ \\
\hline
\end{tabular}



learners. For example, lexical stress may be less problematical for a Bulgarian or Greek speaker and consonant clusters may be a greater problem for Japanese speakers than for Greek speakers. This information can be usefully shared with learners because, according to Dziubalska-Kolaczyk:

Making the learner metalinguistically aware of phonetics and phonology as much as of morphology, syntax, semantics as well as socio-pragmatics will facilitate his/ her acquisition of a second language, i.e. the development of second language competence. (2002: 82)

In other words, awareness-raising may foster improvement with motivated adults and arguably with field experts from non-linguistic disciplines.

\subsection{Functional load}

The concept of functional load also has the potential to help teachers prioritise. Whereas contrastive analysis reveals which features are, or are not, shared between languages, functional load "... is a measure of the work which two phonemes (or a distinctive feature) do in keeping utterances apart" (King 1967: 831). For example, contrastive analysis reveals that "th" does not occur in many languages and therefore suggests that it will be a frequent articulatory problem for speakers. Functional load, however, puts the focus on listeners: how frequently are the dental fricatives of English crucial in distinguishing between two words? Not very frequently, according to Surendran (2003): "th" has a functional load value of 2.3 relative to /t/, 2.0 relative to /d/ and 2.2 relative to $/ \mathrm{z} /$, whereas $/ \mathrm{n} /$ has a functional load value of 12.5 in relation to $/ \mathrm{t} /$ and a value of 13.6 in relation to /s/. For learners, this could be interpreted as follows: it is more important to pronounce a contrast between $/ \mathrm{n} /$ and $/ \mathrm{t} /$ or $/ \mathrm{s} /$ than between "th" and $/ \mathrm{t} / \mathrm{d} / \mathrm{d} /$ or / $z /$; all of the latter are frequent replacements for the dental fricatives. Therefore, large amounts of time should not be devoted to teaching the dental fricative, as the pay-off is small in terms of functional load. ${ }^{3}$ Already in 1991 Brown urged teachers to make use of functional load rankings to prioritise. In 2006 Munro and Derwing started empirically testing the relationship between functional load ranking of segmentals, errors with those segmentals and their impact on listeners' comprehension.

11 However, statistical correlations alone cannot dominate teachers' choices. For example, among many native speakers a failure to pronounce "th" is socially stigmatising (eg. thfronting in Cockney English, think becomes fink). Consequently, some learners may want to invest considerable time and energy in mastering dental fricatives, and teachers should be able to help them move toward such mastery. In the end, it is the teacher's decision or, with experienced adult learners, as in this study, it is a negotiated decision. Enriching contrastive analysis with the functional load of features and their sociolinguistic "weighting" makes for more informed decision-making.

\subsection{Segmentals vs supra-segmentals}

Much of the debate about teaching English pronunciation focuses on the relative importance of segmental or supra-segmental features. For example, this dichotomy appears quite clearly in Scarcella and Oxford (1994). Their article lists items in relation to what is most teachable/learnable, revealing their bias towards supra-segmentals. 
According to them, to communicate intelligibly learners need to master English stress (including loudness, pitch and vowel length), then rhythm, linking and assimilation, and finally sounds (vowels, consonants and consonant clusters) (1994). Scarcella and Oxford also argue that two approaches to teaching pronunciation exist:

\begin{tabular}{|l|l|}
\hline Research-based approach & Traditional approach \\
\hline $\begin{array}{l}\text { Goal = quality of } \\
\text { pronunciation should not } \\
\text { inhibit communication }\end{array}$ & $\begin{array}{l}\text { Goal = acquire native-like } \\
\text { pronunciation }\end{array}$ \\
\hline $\begin{array}{l}\text { Focus on stress and } \\
\text { intonation; not sounds }\end{array}$ & Focus on sounds \\
\hline Teach communicatively & $\begin{array}{l}\text { Non-communicative } \\
\text { teaching of sound } \\
\text { segments (e.g., drills) }\end{array}$ \\
\hline $\begin{array}{l}\text { Teacher provides limited } \\
\text { phonetic descriptions }\end{array}$ & $\begin{array}{l}\text { Phonetic descriptions }= \\
\text { primary component }\end{array}$ \\
\hline $\begin{array}{l}\text { Student's motivation } \\
\text { central. Self-monitoring } \\
\text { skills \& awareness strategies } \\
\text { are taught } \quad \text { Students do not take } \\
\text { responsibility for } \\
\text { improving their own } \\
\text { pronunciation }\end{array}$ \\
\hline $\begin{array}{l}\text { Affect is critical in } \\
\text { pronunciation instruction. } \\
\text { Specific relaxation activities } \\
\text { taught }\end{array}$ & Affect not important \\
\hline
\end{tabular}

13 The authors claim that their research-based approach "is a major break from traditional, audiolingual approaches" (225). However, they do not review data from other studies nor do they provide any data of their own. Perhaps more importantly, the two approaches are not mutually exclusive in the classroom.

14 Teachers should also be aware that, since the early 1990s, there has been a change in the type of research being carried out. Whereas studies used to rely on NS listeners to explore NSs' listening needs (for example Anderson-Hsieh et al. 1992), recently researchers have started to look at how intelligible NSs are to NNSs (eg. Derwing \& Munro 2001; Derwing et al. 2002) and at intelligibility between NNSs (e.g., Jenkins 2000; Seidlhofer 2005a, 2005b; Mauranen 2003). As there are more non-native speakers of English than native speakers in the world, this distinction is important in terms of how teachers interpret research and make choices. In their extensive state-of-the-art article from 2005, Setter and Jenkins conclude that "deviance in the pronunciation of supra-segmentals causes the most difficulty for NSs listeners" (2005: 5) and that "segmentals have a far greater role in English as an International Language ${ }^{4}$ than they do in English as a Foreign Language" ( ibid.). A research-based approach is therefore still valid, but findings from studies using NS listeners do not necessarily apply to NNS listeners, and teachers need to remember this distinction.

\subsection{Jenkins' Lingua Franca Core (LFC)}

15 Jenkins (2000) analysed interactions between NNSs in an attempt to identify those core features necessary for English language communication to proceed comfortably between them. She labeled these features the Lingua Franca Core (LFC) and published her analysis 
as The Phonology of English as an International Language: New Models, New Norms, New Goals. This section looks at some of her much-debated claims, in relation to choices made for the course referred to in the present article.

In her analysis of instances of miscommunication or where communication broke down, Jenkins concluded that "The most important areas for the preservation of mutual phonological intelligibility in ILT $^{5}$ to emerge from the data were the following: Most consonant sounds, appropriate consonant cluster simplification, vowel length distinctions, nuclear stress" (2000: 132). She also found what seems to be a "one-to-one correspondence between what is relevant (crucial to EIL phonological intelligibility) and what is realistic ('teachable' in the sense that learning follows teaching)" (133). However, she cautions that if a feature is difficult it may still be key to intelligibility and therefore, despite being difficult to teach/learn, should somehow be addressed:

Teachers would then need to be informed about which features were not feasible for productive classroom teaching, and ways of introducing these features receptively, so that learners were primed to learn them for themselves should there be future opportunity for them to do so. (134)

Critiques of Jenkins' work sometimes overlook the fact that she repeatedly distinguishes between NNS-NNS and NNS-NS interactions; for example, when NNSs interact, they "are less able to make use of contextual features in their interpretations" (141), so that ambiguity in vowel length distinctions may be more harmful than when NNSs interact with NSs. Overall she advocates a balanced approach to segmentals and suprasegmentals, arguing that on the basis of her data, "the most serious errors are those involving both levels" (2000: 135). However, she does admit that supra-segmentals may be more important for individuals who will interact with native speakers (2000: 136).

The Lingua Franca Core does not concern NNS-NS interactions, which perhaps explains why Jenkins refers to word stress as "a grey area" (150) in that it "seems to be reasonably important to L1 English receivers, but rarely causes intelligibility problems in the ILT data and, where it does so, always occurs in combination with another phonological error" (ibid), such as failure to aspirate a word-initial fortis plosive. Therefore, when speakers are likely to interact with both native and non-native speakers, it may be useful to teach word stress, despite word stress rules being "so complex as to be unteachable" (150). However, Cruttenden states that “... in ordinary connected speech monosyllables account for more than $80 \%$ of words occurring, and hence the number of words whose accentual pattern needs to be learnt is relatively small" (2001: 300). Even Jenkins admits that "the LFC recommends providing learners with a number of general guidelines" (2000: 151) because word stress has an effect on nuclear stress and sound identification. In the exploratory study, basic word stress rules were taught to the participants and these rules were frequently reviewed in tutorials.

19 Although segmentation, intonation and nuclear stress are all included in the LFC, only speech segmentation was systematically addressed with the course participants. The other two features were corrected in context when they led to misunderstandings. Jenkins refers to nuclear stress as crucial to intelligibility in NNS-NNS exchanges because:

It highlights the most salient part of the message, indicating where the listener should pay particular attention. And contrastive stress is especially important in English, as the language does not have the morphological or syntactic resources that many other languages have to highlight contrasts. (2000: 153) 
ex an experiment which confirmed her hypothesis that learners acquire nuclear stress at the receptive level long before they can produce it reliably, Jenkins comes to the conclusion that "overt classroom teaching of rules" is required for nuclear and contrastive stress, because:

Without such teaching, it is probable that (NNSs) will continue to expect nuclear stress to be correctly placed and produced by their peers, but will continue to misplace and misproduce it themselves. This will inevitably cause miscommunication in ILT. (2000: 154)

Overall, Jenkins' work seems to have inspired new interest in the prioritising of pronunciation features and in grounding a pronunciation syllabus in research: surely if learners mastered the features which led to communication breakdowns in such research, then they would be "successful". However, such a list cannot be formulated for several reasons:

- More "such research" still needs to be done and/or replicated;

- The fact that a change in pronunciation does not lead to "visible" evidence of misunderstanding (e.g., speakers correcting each other, requesting reformulation, etc.) does not mean that that change would have no effect on intelligibility in other contexts;

- Likewise, the fact that a change in the pronunciation of, for example a phoneme, did not lead to communication breakdown in one context does not mean that in all contexts that phoneme is unnecessary for successful communication;

- Some of Jenkins' claims may show an RP-bias, e.g., why is vowel length in the LFC core features when it is not distinctive in rhotic varieties?

- Social norms come into play above and beyond basic communicative needs, e.g., failure to pronounce the two "th" sounds can be socially stigmatising and therefore potentially embarrassing for public speakers. More generally, institutional or cultural bias can favour one variety over another, e.g., "RP" over "American" English. Teachers need to be aware of these contextual aspects and take them into account in course design. Jenkins does recognise these potential influences but her admissions do not carry the weight they perhaps should.

Research into the importance of sociolinguistic and socio-psychological factors is a logical complement to work such as Jenkins' on EIL phonology. The expanding interest in such factors also reveals how the debate over "correctness" and norms has evolved. Setter and Jenkins (2005) talk about replacing the notion of "correctness" with "appropriateness":

In this respect, the prevailing concept of 'accent reduction', with its tendency to treat L2 learners as though they are subjects for speech pathology and to encourage them to lose all traces of their L1 accent, is being questioned by those working on the acquisition of international languages, most notable English as an International Language (EIL). The concept of 'accent addition', that is, the adding of L2 pronunciation features to learners' repertoires is, instead, being promoted as one more in keeping with current theories of bilingualism (additive rather than subtractive) and of learner autonomy. (2005: 6)

Thus the debate over segmentals and supra-segmentals could perhaps be addressed by taking an additive rather than a subtractive approach. Critical awareness of a learner's needs as a public speaker could help a teacher choose a core of items to teach, adding features as their learners progress or modify their goals. sections look at their needs when listening to native and non-native speakers. 


\subsection{Speech rate and other measures}

25 definition, as the number of syllables articulated per minute. Anderson-Hsieh and Koehler (1988) examined the effect of increased speech rate for speakers with different degrees of "accented" speech; increased rates led to decreased comprehension and this occurred to a greater degree in relation for the most heavily accented speaker than for the other speakers. Referring to the communication problems arising in classrooms with International Teaching Assistants in North American universities, they state:

While some complaints have been reported about nonnative speech being halting and labored, more frequent complaints have been voiced about nonnative speech that is too fast to understand. ... For example, one engineering professor at Iowa State University reported that he was able to understand the halting English of a recently arrived Chinese advisor better than he could understand his speech a year later when he was speaking more fluently and rapidly. (1988: 562)

Pausing will obviously affect overall speech rate, but it might not impact negatively. Derwing et al. (2007) investigated the effects of inserting 2-second pauses after key lexical terms; in a listening cloze task, comprehension scores improved when pauses were inserted. It is widely acknowledged that listening is a complex process in which listeners call on linguistic and non-linguistic information to make sense of the signal in real time. Strategic use of pausing is teachable and learnable, and could help both speakers and listeners:

The interval between word groups thus not only helps speakers with planning, but also provides crucial support for listeners, by indicating which words they should process together for meaning, and providing them with the time to do so. (Jenkins 2000: 156)

This may be especially important in prepared speech which generally exhibits higher density and lower delivery rates (Nesi 2001). The participants in the exploratory study prepared dense texts and were therefore encouraged to use slower delivery rates.

Pace is defined as the number of stressed words per minute (Vanderplank 1993). It is used here as an indirect indication of whether or not basic sentence stress rules are being observed: elevated pace could indicate that too many words are being stressed and that both lexical words (including given and new information) and structure words are emphasised inappropriately. For many learners, correct tonicity can be quite elusive in spontaneous speech, as, like intonation, it is highly context dependent. In contrast, conference presentations tend to be lexically denser. When faced with such lexically rich read-aloud texts, non-native listeners may be able to use lexical context to resolve tonic stress ambiguity more easily than in conversational speech.

Word stress is also difficult to master productively, which raises the question of whether it should be taught. In their study of 20,000 English words, Cutler and Carter (1987) found that $90 \%$ of all content words in spoken English begin with a stressed syllable. Consequently, it seems beneficial for learners to know that a large proportion of content words in running English are either monosyllabic or stressed on the first syllable. Cutler (1990) speaks of a strong-syllable strategy, where each stressed syllable tends to mark the beginning of a word in English. If word stress constrains lexical access in English (Cooper et al. 2002), this may explain why Hahn (2004) found that native English listeners recall significantly less content when primary stress is incorrect or absent than when primary 
stress is correctly located. Similarly, Cutler and Norris (1988) found that NS listeners are sensitive to the initial position tendency in that they successfully identified word onsets when monosyllabic real words were embedded in disyllabic nonsense words. Fixed lexical stress seems to be a reliable clue to word boundaries - at least for NS listeners. Overall, stress in English is variable and rarely final, whereas French has fixed final word stress. Given this difference, learning some basic English word stress rules should help, for example, native French speakers successfully interact with NSs. This could be especially important when written texts are read aloud, as such texts have a greater proportion of polysyllabic words and longer meaning units/clauses, etc. Misplaced lexical stress may disorient NS listeners when they try to process long, complex sentences. Speakers could thus reduce the cognitive processing load of their NS listeners by mastering a few basic rules and/or by using PowerPoint effectively to provide visual support when the word is first pronounced. Therefore, the exploratory study includes a measure of the proportion of word stress errors.

\subsection{Comprehensibility, intelligibility and accentedness}

In reading research, the terms "comprehension" and "interpretation" are generally used to refer to two different aspects of reading: the first deals with word recognition and the second with meaning construction. Similarly, in spoken language it could be said that the speech stream is perceived and that the content carried by the lexis and the syntax is deciphered. ${ }^{6}$ Moreover, like smudged or faint writing, forms within the speech stream may be perceived but may be unintelligible. This analogy is valuable in course design as teachers seek to define their objectives. The present paper promotes a primary objective of intelligibility and a secondary objective of comprehensibility and the distinction is important.

Comprehensibility and intelligibility, in relation to the interaction between listener and speaker, are explored extensively in a series of studies from Canada: Derwing and Munro, 2005 and 2001; Derwing et al., 2002; Munro and Derwing, 1995 and 2006; Munro et al., 2006. Derwing and Munro clearly define intelligibility as "the extent to which a listener actually understands an utterance" and quantify it as the number of correct words in a transcription task (2005: 385). They also propose two measures of perception, as evaluated in scalar judgment tasks. They define comprehensibility as "a listener's perception of how difficult it is to understand an utterance" (ibid.); for this reason, other researchers frequently refer to it as perceived comprehensibility. Accentedness is defined as "a listener's perception of how different a speaker's accent is from that of the L1 community" (ibid.).Munro and Derwing (1995) found that a marked foreign accent does not always reduce perceived comprehensibility. This is an important finding in terms of speakers' perceptions of their speech. When learners insist that they "don't speak well", it may be that they are referring to the notion of accentedness, e.g., they feel their accent is noticeable and therefore must be "bad".

To the extent that this perception inhibits performance, it needs addressing by the teacher. For the participants of the present study, all three notions were repeatedly demystified, so that the participants understood that having a marked accent did not necessarily mean diminished intelligibility or comprehensibility. They were also encouraged to use certain strategies to counterbalance marked features of their accent, 
e.g., changing syntax to avoid a problematic word stress pattern or finding synonyms which did not have problematic segmentals.

\subsection{Native and non-native listeners}

Many studies have looked at NS comprehension of NNS English (for example, AndersonHsieh and Koehler 1988; Anderson-Hsieh et al. 1992; Munro and Derwing 1995; Hahn 2004), while others have focused on NNS listeners. It is not always clear how they are using the terms comprehensibility and intelligibility, but it is clear that the results are contradictory.

One study found that Spanish speakers listening to Spanish-accented English scored significantly higher than when listening to a NS English accent (Major et al. 2002). However, in the same study the scores of Chinese speakers decreased when they listened to English spoken with a Chinese accent. Another study showed that the comprehension scores of Hong Kong students did not change significantly whether they listened to English with a Hong Kong or RP accent (Tauroza \& Luk, 1997). A recent study by Munro et al. (2006) worked with listeners from native Cantonese, Mandarin, Japanese and English backgrounds. They evaluated the same set of foreign-accented English utterances from NS of Cantonese, Japanese, Polish and Spanish. The study found no consistent intelligibility benefit in listening to English produced by speakers sharing the listener's L1. Their findings support the view that properties in the speech itself are a crucial factor in determining how L2 speech is perceived, even when listeners come from diverse backgrounds.

It seems unclear what degree of native-like pronunciation should be the objective. Perhaps the decision would be easier if teachers went beyond the accuracy-fluency dichotomy and looked at how they define success. That definition should take into account the potential audience(s) their learners will face. Marks speaks of the notion of "comfortable intelligibility" as having:

... gained wide currency as a reasonable goal, and although the concept is by no means unproblematic, depending as it does on so many contextual factors, including the disposition of the listener towards the speaker, it does seem to make sense in an approach that values success over accuracy. (in Lewis 1997: 158)

If accuracy (defined as native-like pronunciation) is to be replaced by success as the goal, success must be defined. Success in the interactions analysed by Jenkins (2000) amounts to exchanges without communication breakdowns and the subsequent need for clarification, repair, etc. Therefore, the real issue is what effect do "non-native" features have on the intelligibility of a speaker's English and to what extent do these differences impact on native and non-native listeners' understanding? For example, if a vowel is mispronounced, is the meaning ambiguous for all listeners? Such ambiguity could be resolved by different types of contextual support: syntactic, lexical, gestural, visual (e.g., PowerPoint slides). These solutions constitute teachable and learnable strategies which any teacher could foster - if avoiding communication breakdown is the goal.

Therefore, the exploratory case study focused on speech rate, pace and word stress, even though the course also included work on speech segmentation, nuclear stress and various segmentals. Two hypotheses are put forward. First, awareness-raising can influence certain features in the productions of motivated, adult learners and these changes will 
endure over extended periods of time. Secondly, speech rate, pace and use of word stress patterns can be modified in minimal contact time.

\section{Exploratory case study}

\subsection{Course organisation}

The programme involved two 3-hour group sessions, one at the beginning and one towards the end of the course, with two or three, half-hour tutorials in between. The programme ended with a mini-conference where each participant did a presentation in English and answered questions. At the beginning of the course a diagnostic recording was made (see Appendix) and each participant received feedback on his/her spoken English. The feedback provided advice on which features to work on for maximum effect. Tutorials were then based on what the participant wanted to work on: formal and informal register, speech segmentation, perception and articulation, interactional functions or vocabulary, etc.

\subsection{Data collection}

Each participant was recorded at the beginning of the course (diagnosis) in January and during the mini-conference in June. Six months after the course, three people were recorded telling an anecdote. Prepared speech before instruction was the formal reading section of Dauer's (1993) diagnostic texts; after instruction it was the participant's miniconference text. Spontaneous speech before instruction was the anecdote section of Dauer's texts; after instruction it was an anecdote recorded six months after the course or it was the question and answer part of the mini-conference (for speakers S2 and S3).

The comparison of prepared and spontaneous speech is problematical because the spontaneous speech of two speakers (S2, S3) was taken from the question \& answer session after the mini-conference, whereas for the other three speakers it was an anecdote. Telling a story with no "priming" for lexis or phonemes is a very different type of speaking, and not only because it is unplanned. Arguably, after doing a conference presentation the speaker is more comfortable with the articulation of certain sounds and may retrieve topic-specific words more quickly. Their pace or speech rate may also be affected by the interactional nature of responding to questions.

Recordings were made on a Sony MZ-R90 mini-disc recorder using a Sennheiser e835 external microphone. Sound files were converted, via Goldwave, into .mp3 files. Recordings were transcribed orthographically by hand. For the mini-conference presentation, a representative, 5-minute section of continuous monologue was transcribed. ${ }^{7}$ Total speaking time was calculated by Goldwave and the number of words and syllables was counted manually by two raters. Individual words were loosely defined as groups of sounds between observable near silences, with ambiguities being resolved under PRAAT-generated waveforms. Accordingly, all hesitation noises, false starts and fillers, regardless of their origin, counted as individual words if they occurred between near silences. 


\subsection{Analysis of results}

The recorded productions were compared for pace and speech rate (before and after instruction) and in two types of speech (prepared and spontaneous). It must be stressed that these findings are not statistically valid, because the sample is small and certain measures are missing. ${ }^{8}$ Future work will analyse longer extracts taken from complete sets of recordings from more participants.

Pace was measured as the overall number of stressed words per minute (swpm). Table 2 shows that, in general, the pace of all the participants was lower in spontaneous speech compared with prepared speech, contrary to Nesi's study (2001) where prepared speech was slower.

Table 2. Pace in Diagnostic Prepared Speech vs. Spontaneous Speech Before and After Instruction (measured in swpm $=$ stressed words per minute)

\begin{tabular}{|c|c|c|c|c|c|c|}
\hline & $\begin{array}{c}\text { Pace: } \\
\text { Prepared } \\
\text { BEFORE }\end{array}$ & $\begin{array}{c}\text { Pace: } \\
\text { Prepared } \\
\text { AFTER }\end{array}$ & $\begin{array}{c}\text { \% and } \\
\text { direction of } \\
\text { change }\end{array}$ & $\begin{array}{c}\text { Pace: } \\
\text { Spontaneous } \\
\text { BEFORE }\end{array}$ & $\begin{array}{c}\text { Pace: } \\
\text { Spontaneous } \\
\text { AFTER }\end{array}$ & $\begin{array}{c}\text { \% and } \\
\text { direction of } \\
\text { change }\end{array}$ \\
\hline S1 & 77.5 & 76.5 & $1 \% \downarrow$ & 55 & 58 & $5 \% \uparrow$ \\
\hline S2 & 79 & 51 & $35 \% \downarrow$ & 42 & 23 & $45 \% \downarrow$ \\
\hline S3 & 63.5 & 32.5 & $49 \% \downarrow$ & X & 52 & X \\
\hline S4 & 91.5 & 76 & $17 \% \downarrow$ & 63 & 53 & $16 \% \downarrow$ \\
\hline S5 & 94.5 & NA & NA & 63.5 & 64 & $<1 \% \uparrow$ \\
\hline
\end{tabular}

However, given that Nesi was dealing with native or near-native speakers, it is not surprising that non-native speakers would take more time to formulate sentences spontaneously. The only anomaly was $\mathrm{S} 3$, whose pace after instruction was actually lower for prepared speech (32.5 swpm) than for spontaneous speech (52 swpm). S3 had a relatively marked accent and had been instructed to slow down in order to accommodate listeners' potential needs.

Instruction did not seem to effect S1's pace for prepared speech (1\% decrease), and the change in spontaneous speech was minor (5\% increase). On the other hand, S2 slowed her pace considerably in both prepared speech (35\% change) and in spontaneous speech ( $45 \%$ change). This had the effect of giving her speech a more natural rhythm, as she used more weak forms and did not highlight as much given information, which could conceivably facilitate listening in English L1 listeners. S4 reduced her pace quite noticeably in both prepared speech (17\% change) and in spontaneous speech (16\% change). Interestingly, before instruction, the pace of the Greek NS (S5, 94.5 and 63.5 swpm) was similar to the pace of the Japanese NS (S4) for both prepared (91.5 swpm) and spontaneous speech (63 swpm); this may simply be due to individual characteristics but the effect of the L1 could be worth examining in a larger population. 
Speech rate is defined as the number of syllables per second (sps). Percentages of change varied widely, as shown in Table 3. Speech rate, like pace, was higher for prepared speech than it was for spontaneous speech after instruction for all participants, except for S2 (2.1 // 2.18) and S4 (2.5 // 2.05).

Table 3. Speech Rates Before and After Instruction for Prepared Speech vs. Spontaneous Speech ( measured in sps $=$ syllables per second)

\begin{tabular}{|l|c|c|c|c|c|c|}
\hline & $\begin{array}{c}\text { Speech } \\
\text { Rate: } \\
\text { Prepared, } \\
\text { BEFORE }\end{array}$ & $\begin{array}{c}\text { Speech } \\
\text { Rate: } \\
\text { Prepared, } \\
\text { AFTER }\end{array}$ & $\begin{array}{c}\text { \% and } \\
\text { direction } \\
\text { of change }\end{array}$ & $\begin{array}{c}\text { Speech Rate: } \\
\text { Spontaneous, } \\
\text { BEFORE }\end{array}$ & $\begin{array}{c}\text { Speech Rate: } \\
\text { Spontaneous, } \\
\text { AFTER }\end{array}$ & $\begin{array}{c}\% \text { and } \\
\text { direction } \\
\text { of change }\end{array}$ \\
\hline S1 & 3.16 & 3.22 & $2 \% \uparrow$ & 2.43 & 2.19 & $10 \% \downarrow$ \\
\hline S2 & 3.29 & 2.1 & $36 \% \downarrow$ & 1.93 & 2.18 & $13 \% \uparrow$ \\
\hline S3 & 2.67 & 2.38 & $11 \% \downarrow$ & NA & 2.04 & NA \\
\hline S4 & 3.47 & 2.4 & $31 \% \downarrow$ & 2.05 & 2.05 & $0 \%$ \\
\hline S5 & 3.64 & NA & NA & 2.95 & 2.6 & $12 \% \downarrow$ \\
\hline
\end{tabular}

S2 dramatically reduced her prepared speech rate (36\% decrease), but increased her spontaneous speech rate (13\%). This increase may reflect the fact that she was responding to questions and not telling a story:

they can express the two langua'ges at the same time and that's 'specific to bimodal bilinguals euh especially deaf people or hearing people uhm which wh hearing people who who know can sign yes yes but code-ruling code-switching uh we can we can keep the the term uh but the that is in cross-modal bilingua'lism privace very rare

48 The presence of numerous polysyllabic words in unplanned speech represents an articulatory challenge but may show that doing the presentation has increased her ease in using these words afterwards. In contrast, S4's spontaneous speech rate was identical before and after instruction ( $2.05 \mathrm{sps})$; this may be due to the fact that both spontaneous samples were anecdotes.

S1's speech rate for prepared speech increased by $2 \%$ after instruction but she showed a $10 \%$ decrease in spontaneous speech. Similarly, S5 decreased her speech rate in spontaneous speech after instruction by $12 \%$ :

we are not staying in a same house// hopefully// ah ssss she's studying um she's doing a $\mathrm{PhD} / /$ thesis on psychology and especially on language development and her re'search field has to $d$ is about um// troubles not troubles let's say difficulties in uh language development in children

50 Here the challenge is not articulating sounds, but rather finding elements (ideas, words, structures) and constructing a coherent description.

51 Overall, the participants' spontaneous pace and speech rate are lower than their prepared speech measures, in contrast with Nesi's findings (based on native or near-native speakers), where conversation was characterised by higher speed and lower lexical 
density than prepared speech (2001). However, spontaneous speaking involves retrieving words and structures as well as real-time organising. In learners' productions, in which learners must also manage certain articulatory constraints, this extra processing may explain the slower productions for unrehearsed speech, despite the fact that spontaneous speech tends to be lexically and propositionally less dense than prepared, formal academic speech.

The lexical density (LD) of the mini-conference presentations was calculated by dividing the number of lexical words in a text by the number of running words, following Stubbs (1986). Table 4 shows that the density of the participants' presentations was slightly higher or much higher than in comparable BASE lectures (41.3-49.2\%) (Nesi, 2001).

Table 4. Lexical Density and Speed of Delivery of Mini-conference Presentations ${ }^{9}$

\begin{tabular}{|c|c|c|}
\hline Participants & $\begin{array}{c}\text { Lexical Density } \\
\text { (lexical/running words) }\end{array}$ & $\begin{array}{c}\text { Speed of Delivery } \\
\text { (words per minute }\end{array}$ \\
\hline S1 (Bulgarian L1) & $51.8 \%$ & 110 \\
\hline S2 (French L1) & $61 \%$ & 97 \\
\hline S3 (French L1) & $56.3 \%$ & 94 \\
\hline \hline S4 (Japanese L1) & $65.8 \%$ & 105 \\
\hline
\end{tabular}

Inversely, the participants' speed of delivery is less than or within the "slower than normal" level (100 wpm) or "moderately slow" level (100-125 wpm) proposed by Tauroza and Allison (1990), and is markedly lower than the English and Comparative Literature lectures from the BASE lectures (147.2 and $170.4 \mathrm{wpm}$ ) (Nesi, 2001). The speakers may have been having articulatory difficulties with their rehearsed text, or they may have been anticipating their listeners' needs and adapted their speech to reduce their listeners' cognitive processing load. In the tutorials, the participants became aware that some of the phonetic and phonological features of their speech could cause comprehension problems, so they may have focused on an easily modifiable aspect of their speech: their speed of delivery, or speech rate.

When all three measures are compared (lexical density, speech rate, pace), the relationship is not clear. S1 had the lowest LD but the highest pace (76.5) and the highest rate (3.22). S4 had the highest LD but the second highest pace (76) and the second highest speech rate (2.4). S3 had a much lower LD than S4 but an identical speech rate. The present sample is too small to determine how much of this is due to the variation of individual speakers, to the influence of L1s and/or to the nature of the task.

The percentage of word stress errors was calculated by dividing the number of words by the total number of polysyllabic words in the text. This percentage is expressed in Table 5 for the tokens not the types. 
Table 5. Word Stress Errors in Prepared Speech vs. Spontaneous Speech Before and After Instruction, expressed as percentages of tokens ${ }^{10}$

\begin{tabular}{|l|c||c|c|c|}
\hline & Prepared: BEFORE & Prepared: AFTER & Spontaneous: BEFORE & Spontaneous: AFTER \\
\hline S1 & $0 \%$ & $1.5 \%$ & $9.5 \%$ & $3 \%$ \\
\hline \hline S2 & $17.5 \%$ & $18 \%$ & $18 \%$ & $15 \%$ \\
\hline \hline S3 & $23 \%$ & $29 \%$ & NA & $19 \%$ \\
\hline S4 & $2.5 \%$ & $3 \%$ & $2 \%$ & $5 \%$ \\
\hline \hline S5 & $0 \%$ & NA & $1 \%$ & $1 \%$ \\
\hline
\end{tabular}

56 Although one might expect spontaneous speech to be less lexically dense with fewer polysyllabic words and fewer potential errors, the figures show the opposite, probably because these are non-native speakers. For example, s1's diagnostic recording of prepared speech was free of word stress errors. However, in spontaneous speech before instruction she made $9.5 \%$ errors, improving to $3 \%$ afterwards. The sample is too small to determine how much of this is due to explicit awareness training or individual variation.

Going beyond quantifiable changes, it is interesting to look at the word stress errors of S2 and S4 in terms of a willingness to take risks (to use polysyllabic words). For example, S2's percentage of errors $(17.5 \%, 18 \%$ and $18 \%)$ is remarkably similar across the types of spoken data, dropping marginally to $15 \%$ in spontaneous production after instruction. Similarly, the Japanese speaker (S4) held relatively steady $(2.5 \%, 3 \%, 2 \%)$ across the spoken text types but then made marginally more mistakes in the spontaneous task (5\%) six months after the end of the course. S4 was obviously struggling to separate her French L2 from her English L2 but did not seek to avoid polysyllabic words. The words in italics were pronounced à la française:

I'll talk about my euh research I'll th subject is um the 'phenomenus phéno'mène of inversion ... I hope that I will finish by tomorrow night uh and Saturday ap Saturday matin Saturday morning euhm I wi I should take the TG TJV of cinq o'clock five o'clock I'll I'll st I'll leave with the train of at sign at five o'clock huh so

Despite the slight increase in errors and numerous false starts, the obvious willingness to "jump right in" could indicate an increase in confidence, which is also evident in S2's productions.

\section{Conclusion and future directions}

This paper describes the choices made in the design of an English pronunciation shortcourse for researchers, showing the usefulness of contrastive analysis, of considering learners' perceived needs and of critically evaluating current research (especially into listeners' needs) when designing such a course. This involved consideration of related issues, such as variation in writing and speech, listeners' needs, the concepts of intelligibility, comprehensibility and accentedness, and definitions of accuracy and success. 

stress for five participants. However, interpretations based on the present research can only be tentative, as the sample is so small. Nevertheless, the results support the first general hypothesis: awareness-raising in minimal contact time can influence production over a period of six months. Further work is needed to examine changes in more speakers over longer periods of time. Evidence was also found that speech rate, pace and use of word stress patterns could be modified, although not always in the predicted direction. Individual speaker effects probably play a role in explaining the results, as do languagespecific features. Further studies could use intelligibility ratings to investigate the importance of de-accenting given information, or to look at pace in relation to location and appropriateness of tonicity. Additionally, Derwing and Munro's research on the interactions between intelligibility, comprehensibility and accentedness could be usefully replicated in a European context.

61

Word stress habits may be the most difficult of the three features to durably modify for certain speakers. However, if word stress has high functional load (and research would seem to suggest this could be true, at least for NS listeners) teaching should take this into account. For example, speakers can be encouraged to use synonyms for terms they have difficulty stressing correctly, and/or to point to words on a PowerPoint slide, and/or to insert a 2-second pause before and after difficult words in order to give listeners time to process the signal. All of these solutions are teachable and learnable, and they are likely to minimise the impact that speakers' articulatory difficulties have on listeners' processing of the signal.

The task of reading aloud a lexically dense, written text seems extremely artificial. However, proactively preparing for such a situation can increase the perceived chances of overall success and this is an important motivational factor. Just as importantly, when speakers rehearse in order to reduce listeners' cognitive load, rather than to feel more comfortable pronouncing certain words, their attention is focused on intelligibility rather than accuracy. The participants in this study mentioned that, as well as feeling more comfortable during their presentation, they also felt more prepared to face people's questions. Some of the participants who have attended the course for two or three years have moved on from reading aloud to speaking comfortably from notes or slides. Consequently, although reading aloud perverts the nature of written text, it can be considered a feasible first step in presenting at international conferences; given the pressure on researchers to achieve worldwide recognition, the motivational importance of this should not be ignored.

63 A pressing institutional recommendation also arises from this analysis. Teachers need adequate training not just in phonetics and pronunciation teaching, but also in critically understanding research (educational, psycholinguistic, sociolinguistic, etc.), in order to ground their choices. They cannot rely on intuition and experience alone, and research results can be contradictory. 


\section{BIBLIOGRAPHY}

Anderson-Hsieh, J. R and K. Koehler. 1988. "The effect of foreign accent and speaking rate on native speaker comprehension". Language Learning 38/4, 561-593.

Anderson-Hsieh, J. R. et al. 1992. "The relationship between native speaker judgments of nonnative pronunciation and deviance in segmentals, prosody and syllable structure". Language Learning 42/4, 529-555.

Banks, D. 1999. "Becoming part of the network: French scientists and the use of English at conferences". ASp 23-26, 209-220.

Biber, D. 1988. Variation across Speech and Writing. Cambridge: Cambridge University Press.

Brown, A. 1991. "Functional load and the teaching of pronunciation". In Brown, A. (ed.). Teaching English Pronunciation: A Book of Readings. London: Routledge, 221-224.

Chafe, W. and J. Danielewicz. 1987. "Properties of spoken language." In Horowitz, R. and S. J. Samuels (eds.). Comprehending Oral and Written Language. New York: Academic Press, 83-113.

Cooper, N., A. Cutler and R. Wales. 2002. "Constraints of lexical stress on lexical access in English: Evidence from native and non-native listeners”. Language and Speech 45, 207-228.

Cruttenden, A. 2001. Gimson's Pronunciation of English. $6^{\text {th }}$ ed. London: Arnold.

Cutler, A. 1990. "Exploiting prosodic possibilities in speech segmentation." In G.T.M. Altmann (ed.). Cognitive Models of Speech Processing. Cambridge, MA: MIT.

Cutler, A. and D. Carter. 1987. "The predomination of strong initial syllables in the English vocabulary". Computer Speech and Language 2, 133-142.

Cutler, A. and D. Norris. 1988. "The role of strong syllables in segmentation for lexical access". Journal Experimental of Psychology: Human Perception and Performance 14, 113-121.

Danielewicz, J. M. 1984. "The Interaction between text and context: A study of how adults and children use spoken and written language in four contexts". In Pellegrini, A.D. (ed.). The Development of Oral and Written Language: Readings in Developmental and Applied Psycholinguistics. Norwood, NJ: Ablex, 243-260.

Dauer, R. M. 1993. Accurate English: A Complete Course in Pronunciation. New York: Prentice Hall Ltd.

Derwing, T. M. et al. 2002. "Teaching native speakers to listen to foreign-accented speech". Journal of Multilingual and Multicultural Development 23/4, 245-259.

Derwing, T. M. et al. 2007. “A Longitudinal Study of ESL Learners' Fluency and Comprehensibility Development”. Applied Linguistics (AdvanceAccess published online on December 12, 2007).

Derwing, T. M. and M. J. Munro. 2001. "What speaking rates do non-native listeners prefer?" Applied Linguistics 22/3, 324-337.

Derwing, T. M. and M. J. Munro. 2005. “Second language accent and pronunciation teaching: A research-based approach”. TESOL Quarterly 39, 379-397.

Desrichard, O. 2008. E-mail to the author. May 15, 2008. 
Dimitrova, S. 1997. "Bulgarian speech rhythm: Stress-timed or syllable-timed? = Le rythme du discours en bulgare : Cadencement accentuel ou syllabique ?". Journal of the International Phonetics Association 27/1-2, 27-33.

Dziubalska-Kolaczyk, K. 2002. "Speech is in the ear of the listener: Some remarks on the acquisition of second language sounds". In Hales, K., A. Terveen et al. (eds.). Selected papers from the Sixth College-wide Conference for Students in Languages, Linguistics and Literature 2002. Honolulu: University of Hawai i at Manoa, 81-92.

Hahn, L. D. 2004. "Primary stress and intelligibility: Research to motivate the teaching of suprasegmentals". TESOL Quarterly 38, 201-223.

Halliday, M.A.K. [1985] 1989. Spoken and Written Language. Oxford: Oxford University Press.

Jenkins, J. 2000. The Phonology of English as an International Language: New Models, New Norms, New Goals. Oxford: Oxford University Press.

Jenkins, J. 2002. “A sociolinguistically based, empirically researched pronunciation syllabus for English as an International Language”. Applied Linguistics 23/1, 83-103.

Jenkins, J. 2007. English as a Lingua Franca: Attitude and Identity. Oxford: Oxford University Press. Joseph, B. D. and I. Philippaki-Warburton. 1987. Modern Greek. London: Croom Helm Publishers. King, R.D. 1967. “Functional load and sound change”. Language 43, 831-852.

Kormos, J. and M. Dénes. 2004. "Exploring measures and perceptions of fluency in the speech of second language learners”. System 32, 145-164.

Lewis, M. 1997. Implementing the Lexical Approach: Putting Theory into Practice. Hove, England: LTP.

Major, R.C. et al. 2002. "The effect of nonnative accents on listening comprehension: implications for ESL assessment”. TESOL Quarterly 36, 173-190.

Marks, J. 1997. “Classroom Report Number 4". In M. Lewis, Implementing the Lexical Approach: Putting Theory into Practice. Hove, England: LTP, 156-162.

Masayoshi, S. 1990. The Languages of Japan. Cambridge: Cambridge University Press.

Mauranen, A. 2003. “Academic English as lingua franca - a corpus approach”. TESOL Quarterly 37, 513-27.

Munro, M.J. and T. M. Derwing. 1995. "Foreign accent, comprehensibility, and intelligibility in the speech of second language learners". Language Learning 45 73-91.

Munro, M.J. and T. M. Derwing. 2006. "The functional load principle in ESL pronunciation instruction: An exploratory study”. System 34, 520-531.

Munro, M. J. et al. “The mutual intelligibility of L2 speech". SSLA 28, 111-131.

Nesi, H. 2001. “A corpus-based analysis of academic lectures across disciplines”. In Cotterill, J. and A. Ife (eds.). Language across Boundaries: Selected papers from the Annual Meeting of the British Association for Applied Linguistics. Cambridge: Anglia Polytechnic University, September 2000, 201-218.

Rogerson, P. and J. B. Gilbert. 1990. Speaking Clearly. Cambridge: CUP.

Scarcella, R. C. and R. L. Oxford. 1994. "Second language pronunciation: state of the art in instruction". System 22/2, 221-230.

Seidlhofer, B. 2005a. "English as a Lingua Franca". ELT Journal 59/4, 339-341. 
Seidlhofer, B. 2005b. "Language variation and change: the case of English as lingua franca". In Dziubalska-Kolaczyk, K. and J. Przedlacka (eds.). English pronunciation models: a changing scene. Bern: Peter Lang, 59-75.

Setter, J. and J. Jenkins. 2005. "State-of-the-art review article”. Language Teaching 38, 1-17. Stubbs, M. 1986. "Lexical density: a technique and some findings". In M. Coulthard (ed.) Talking about Text, Discourse Analysis Monograph no. 13, ELR, University of Birmingham, 27-42, In Nesi, H. 2001. "A corpus-based analysis of academic lectures across disciplines". In Cotterill, J. and A. Ife (eds.). Language across Boundaries: Selected papers from the Annual Meeting of the British Association for Applied Linguistics. Cambridge: Anglia Polytechnic University, September 2000, 201-218.

Surendran, D. 2003. The Functional Load of Phonological Contrasts, Unpublished Master's Thesis, Department of Computer Science, University of Chicago <http://people.cs.uchicago.edu/ dinoj/ research/fload/>.

Swan, M. and B. Smith (eds.). 2001. Learner English: A teacher's guide to interference and other problems. Cambridge: CUP.

Tauroza, S. and D. Allison. 1990. "Speech rates in British English". Applied Linguistics 11/1, 90-105 In Nesi, H. 2001. "A corpus-based analysis of academic lectures across disciplines". In Cotterill, J. and A. Ife (eds.). Language across Boundaries: Selected papers from the Annual Meeting of the British Association for Applied Linguistics. Cambridge: Anglia Polytechnic University, September 2000, 201-218.

Tauroza, S. and J. Luk. 1997. “Accent and second language listening comprehension”. RELC Journal $28,54-71$.

Vanderplank, R. 1993. "Pacing and spacing as predictors of difficulty in speaking and understanding English". English Language Teaching Journal 47, 117-125.

\section{APPENDIXES}

\section{Diagnostic Speech Sample (Dauer 1993)}

\section{Part A (Formal Reading)}

Learning to speak a foreign language fluently and without an accent isn't easy. In most educational systems, students spend many years studying grammatical rules, but they don't get much of a chance to speak. Arriving in a new country can be a frustrating experience. Although they may be able to read and write very well, they often find that they can't understand what people say to them. English is especially difficult because the pronunciation of words is not clearly shown by how they're written. But the major problem is being able to listen, think, and respond in another language at a natural speed. This takes time and practice.

\section{Part B (Informal Dialogue)}

A: Hi, Bob. Gee, I haven't seen you in a while. How are you doing?

B: Not so good. Unfortunately, I've had a bad cold for the last three or four days, and I feel a little tired. How about you? What have you been up to recently?

A: Well, I just came back from a weekend at the shore. Do you know Liz? She invited me out to her family's place on Martha's Vineyard. 
B: Is her house on the beach or in town?

A: It's a few minutes away from a big beach on the south coast. We usually walked out there in the morning, brought sandwiches and soft drinks with us, and stayed all day.

B: I've heard enough! Would you take me along some time?

A: With pleasure.

\section{Part C (Free Speech)}

Give a short, two-minute speech about one of the following topics: an embarrassing or humorous situation that you had with the English language or culture; an interesting or unusual experience that you had over vacation; your first day in this country, at this university, or at your job; your problems speaking English and why you're taking this course; define a technical term or describe a process related to your professional field.

\section{NOTES}

1. Baselines for the present study were drawn from Nesi (2001) because, even though it seems that the BASE lecturers were native speakers, no baselines could be found for non-native lectures. "Each broad discipline area (Science, Social Science and Humanities) was represented by ten lectures, spoken with a variety of accents, mostly British but also North American and Asian" (ibid. : 206).

2. Information compiled from a variety of sources: Swan and Smith 2001; Masayoshi 1990; Joseph and Philippaki-Warburton 1987; Dimitrova 1997; Rogerson and Gilbert 1990.

3. Jenkins states that these common substitutions for the universally difficult dental fricatives reveal an L1 transfer that "will not impair intelligibility (even if it is at present stigmatized by educated L1 speakers of English)" (2000, 101).

4. English as an International Language can be shortened to EIL, an acronym which is often used interchangeably with ELF (English as a Lingua Franca).

5. For Jenkins, ILT refers to "the speech of NBEs (non-bilingual English speakers) from different L1s as they engage in interaction" (2000: 19).

6. The degree to which this processing is serial or simultaneous is not at issue here.

7. The informal setting meant that several recordings were marred by a disrupted flow of speech (e.g., doors opening and closing, the computer cord being tripped over) and by interactional sections (jokes and laughter, etc.); further research will involve transcription of entire recordings.

8. The spontaneous measures before instruction are lacking for $\mathrm{S} 3$ because she simply forgot to record those sections. The prepared measures after instruction are missing for S5 because she used notecards; without video evidence it would have been impossible to know whether she was reading aloud or speaking spontaneously.

9. The data for S5 is excluded here because she improvised a large proportion of her presentation.

10. No prepared measure after instruction could be calculated for S5 because it was not clear when she was reading and when she was improvising, and S3 did not do the recording for spontaneous speech before instruction. 


\section{ABSTRACTS}

English teachers are frequently asked to help colleagues prepare presentations for international conferences. Sometimes this assistance takes the form of a language course or tutorials focusing on the spoken language. Contact time is short but the participants are highly motivated. What type of pronunciation work will provide the greatest payoff in terms of successfully being understood when speaking English to an international audience? Given the current debate on norms and varieties - spurred on by the work of Jenkins $(2000,2002,2007)$ and other proponents of English as a Lingua Franca - how can teachers ground their course design in research? This paper addresses a variety of issues concerning the design of pronunciation courses which focus on maximum intelligibility for both native speakers and non-native speakers. Reference is made to an exploratory study of a particular course for researchers in applied linguistics, in order to illustrate some of the issues. Directions for further research are described.

Les enseignants d'anglais sont fréquemment appelés à aider leurs collègues à préparer des communications pour des colloques internationaux. Parfois, cette aide prend la forme de cours de langue, ou encore de séances individuelles, centrés sur l'oral. Si le temps d'échange est toujours restreint, les participants témoignent d'une grande motivation pour participer à ces travaux. Comment optimiser un travail axé sur la prononciation dans la perspective d'être compris en anglais par un auditoire international ? Face au débat actuel sur les normes et les variétés de l'anglais, impulsé par Jenkins $(2000,2002,2007)$ et d'autres promoteurs de l'anglais en tant que Lingua Franca, comment mieux fonder ces pratiques pédagogiques? Cette contribution traite de plusieurs questions concernant la conception d'un cours d'anglais parlé qui prend pour objectif une intelligibilité maximale auprès d'un public tant natif que non natif. Afin de traiter cette problématique, une étude préliminaire relative à un cours d'anglais ciblé sur un public de chercheurs en linguistique et en didactique est présentée. Des pistes pour des recherches ultérieures sont également proposées.

\section{INDEX}

Mots-clés: communication de congrès, conception de cours, intelligibilité, Lingua Franca Core, prononciation, public non natif

Keywords: conference presentation, course design, intelligibility, non-native speaker, pronunciation

\section{AUTHOR}

\section{ALICE HENDERSON}

Alice Hendersonis a Senior lecturer at Université de Savoie, where she teaches academic English for specialists and for students in the Humanities and Social Sciences. Her research interests span the pedagogy of oral language, oral and written expression, and corpus linguistics.

alice.henderson@univ-savoie.fr 